\title{
Transforming race-based health research in Canada
}

\author{
Geetanjali Datta MPH ScD, Arjumand Siddiqi MPH ScD, Aisha Lofters MD PhD
}

- Cite as: CMAJ 2021 January 18;193:E99-100. doi: 10.1503/cmaj.201742

$\mathbf{T}$ he coronavirus disease 2019 pandemic has laid bare some of the ways in which social structures lead to inequalities in health. It has also revealed Canada's poor infrastructure for tracking and addressing race-based inequalities across health outcomes. Canada has been slow to acknowledge the role that structural racism plays in our society and how that racism serves to generate and perpetuate inequalities, including in health. Decisive action is required to develop our research capacity to assess and eliminate race-based inequalities in health. The Canadian Institutes of Health Research (CIHR), the country's leading health research investment agency, has the power to take such action and should do so by establishing an Institute of Racism and Health.

Canada's history with structural racism stems from its colonial past, during which both Indigenous peoples and people of African descent were enslaved. ${ }^{1,2}$ The impact of this history persists today, as evidenced by the 2017 report of the United Nations Working Group of Experts on People of African Descent on its mission to Canada, ${ }^{3}$ which stated that, despite Canada's reputation for being an inclusive society, "anti-Black racism and racial stereotypes ... are so deeply entrenched in institutions, policies and practices, that its institutional and systemic forms are either functionally normalized or rendered invisible, especially to the dominant group." ${ }^{3}$ In 2018, the Canadian Public Health Association acknowledged its own role in perpetuating systemic racism and stated in its report that "anti-Black racism is ubiquitous in many Canadian institutions and is responsible for perpetuating contemporary Black poverty and unemployment, racial profiling, law enforcement violence, incarceration, immigration detention, deportation, exploitative migrant labour practices, disproportionate child removal and low graduation rates." ${ }^{\text {"Y }}$ Yet, although social determinants of health such as income and immigration or educational status are often researched, the influence of race or racism on health has not been extensively studied in Canada.

There is relatively limited but telling scholarship on race-based inequalities in health in Canada. ${ }^{5,6}$ Herein, when we refer to race, we recognize that race is socially constructed and refers to the phenomenon whereby people of certain races become racialized through systematic differential treatment, differential access to resources and differential access to opportunities, which accumulates across

\section{KEY POINTS}

- Racism remains prevalent in Canada and it underpins health inequalities that are under-studied.

- The Canadian Institutes of Health Research, the country's leading health research investment agency, could address this by establishing an Institute of Racism and Health.

- Canadian health research should begin focusing on racism as a determinant of health and acknowledge that it is not adequate to fold issues of racism in with the very real concerns that face immigrant populations.

the lifecourse. ${ }^{7}$ This concept of race is sometimes conflated with a misguided, genetic conceptualization whereby observed racial differences are attributed to purported genetic differences. However, scientific evidence has long shown this genetic conceptualization of race to be flawed. ${ }^{8,9}$ Racial and ethnic inequalities in several outcomes have been noted in Canada, including cardiovascular disease, cancer and diabetes. However, much of the current scholarship focuses on immigrant populations, which have distinct and sometimes overlapping experiences as native-born visible minorities. If we are serious about addressing race-based inequalities, we will need to substantially increase the quantity and quality of research on the topic. A fundamental barrier to this is the lack of explicit funding and infrastructure, including for data collection, to support research on the effects of racism.

We propose that Canada commit to the dedicated study of the impact of racism and antiracist initiatives on health by creating an Institute of Racism and Health within the CIHR. The CIHR Institute of Gender and Health and the Institute of Indigenous Peoples' Health serve as good examples of the importance of thematic, population-specific institutes within Canada, upon which a research infrastructure related to racism and health could be modelled. The Institutes of CIHR are networks of researchers brought together to focus on specific areas of concern in order to guide future research. Under the umbrella and support of $\mathrm{CIHR}$, the Institutes have developed strategic plans and related goals, receive the benefit of expertise from advisory boards, lead and support knowledge-translation initiatives and 
provide explicit research funding, training and toolkits for Canadian researchers. The Institute of Indigenous Peoples' Health has engaged community voices in developing priorities for health research involving Indigenous populations and has worked with other $\mathrm{CIHR}$ institutes on developing research initiatives that target the needs of Indigenous communities. ${ }^{10}$ Similarly, the Institute of Gender and Health has developed several cross-Institute research initiatives, developed mandatory training modules, and has become an international leader in improving the use of sex and gender in health research. ${ }^{11}$

As structural racism is prevalent across the globe, we can also look to examples internationally. In the United States, the National Institutes of Health created the National Institute of Minority Health and Health Disparities in 2010, after being established as an Office in 1990 and a Center in 2000. Since 2010, the body has funded more than 1200 research grants and currently funds research conducted at 200 sites nationally and internationally. ${ }^{12}$

As noted above, we would be premature to presume that issues regarding structural racism and its impact on health are less pronounced in Canada than in other jurisdictions, especially given any lack of strong evidence to the contrary.

CIHR recently released a letter to the Canadian research community detailing its current and intended efforts to address some of the problems arising from structural racism. ${ }^{13}$ Current discourse has centred on increasing the diversity of the research workforce and developing trans-Institute initiatives. Although these are welcome steps, they are insufficient. Tackling structural racism will require strategic, coordinated planning and action, coupled with the type of intellectual and financial resources afforded a dedicated CIHR Institute. Canada does not yet possess the breadth and depth of expertise necessary to address issues regarding racism and health adequately if spread out across Institutes. However, it can eventually reach this goal by investing in an institute that would support in-depth training for those who would like to dedicate their careers to this area of research, as well as required training for all researchers, much like current training on sex and gender, so as to improve broad considerations of racism and health in research across domains.

Health researchers, practitioners and decision-makers should not shy away from the real challenges of studying the effects of racism in Canada. It is time to begin focusing on racism as a determinant of health and acknowledge that it is not adequate to fold issues of racism in with the very real concerns that face our immigrant populations. We must name the problem of racism so as to create solutions aimed at addressing it directly. If the structures of Canada's past have led to systems that are biased, Canada must create new structures that are sufficiently funded and supported to begin the enormous effort of rectifying long-standing inequalities.

\section{References}

1. Williams D. When it come to systemic racism, history belies your words, Mr Legault. CBC News Montreal 2020 June 13. Available: www.cbc.ca/news/canada/ montreal/systemic-racism-quebec-historian-1.5608397 (accessed 2020 Nov. 10).
2. Cooper A. The hanging of Angélique: the untold story of Canadian slavery and the burning of Old Montréal. Athens (GA): University of Georgia Press; 2007.

3. Human Rights Council; Working Group of Experts on People of African Descent. Report of the Working Group of Experts on People of African Descent on its mission to Canada. New York: United Nations Dag Hammarskjöld Library; 2017.

4. Advocacy position statements: racism and public health. Ottawa: Canadian Public Health Association; 2018.

5. Khan MM, Kobayashi K, Vang ZM, et al. Are visible minorities invisible in Canadian health data and research? A scoping review. Int J Migr Health Soc Care 2017; 13:126-43.

6. Nestel S. Color coded health care: the impact of race and racism on Canadians' health. Toronto: Wellesley Institute; 2012.

7. Sharma M, Kuper A. The elephant in the room: talking race in medical education. Adv Health Sci Educ Theory Pract 2017;22:761-4.

8. Boyd RW, Lindo EG, Weeks LD, et al. On racism: a new standard for publishing on racial health inequities [blog]. Health Aff (Millwood) 2020 July 2. Available: www. healthaffairs.org/do/10.1377/hblog20200630.939347/full/ (accessed 2020 Nov. 10).

9. Mersha TB, Beck AF. The social, economic, political, and genetic value of race and ethnicity in 2020. Hum Genomics 2020;14:37.

10. Canadian Institutes of Health Research. Institute of Indigenous Peoples' Health Strategic Plan 2019-2024. Ottawa: Canadian Institutes of Health Research; 2019.

11. Canadian Institutes of Health Research Institute of Gender and Health. Science is better with sex and gender: Strategic Plan 2018-2023. Ottawa: Canadian Institutes of Health Research; 2018.

12. National Institute on Minority Health and Health Disparities Fact Sheet. Bethesda (MD): National Institutes of Health; 2020.

13. Clifford T. CIHR's commitment to enhancing equity, diversity, and inclusion in the research funding system. Ottawa: Canadian Institutes of Health Research; modified 2020 Oct. 14. Available: https://cihr-irsc.gc.ca/e/52174.html (accessed 2020 Oct. 15)

Competing interests: Arjumand Siddiqi is Canada Research Chair in Population Health Equity and Aisha Lofters is Chair in Implementation Science at the Peter Gilgan Centre for Women's Cancers at Women's College Hospital in partnership with the Canadian Cancer Society. No other competing interests were declared.

This article has been peer reviewed.

Affiliations: Department of Social and Preventive Medicine (Datta), Université de Montréal; Health Innovation and Evaluation Hub (Datta), CRCHUM, Montréal, Que.; Department of Medicine (Datta), Cedars-Sinai Medical Center, Los Angeles, United States; Dalla Lana School of Public Health (Siddiqi), University of Toronto; Hospital for Sick Children Research Institute (Siddiqi); Women's College Hospital (Lofters); Department of Family and Community Medicine (Lofters), Faculty of Medicine, University of Toronto, Toronto, Ont.

Contributors: All of the authors contributed to the conception and design of the work, drafted the manuscript, revised it critically for important intellectual content, gave final approval of the version to be published and agreed to be accountable for all aspects of the work.

Content licence: This is an Open Access article distributed in accordance with the terms of the Creative Commons Attribution (CC BY-NCND 4.0) licence, which permits use, distribution and reproduction in any medium, provided that the original publication is properly cited, the use is noncommercial (i.e., research or educational use), and no modifications or adaptations are made. See: https://creativecommons.org/ licenses/by-nc-nd/4.0/

Acknowledgement: The authors acknowledge Dr. Onye Nnorom, President of the Black Physicians' Association of Ontario, for providing input on a previous version of this commentary.

Correspondence to: Geetanjali Datta, geetanjali.datta@cshs.org 